\title{
Adaptive Integral Second-Order Sliding Mode Control Design for Load Frequency Control of Large-Scale Power System with Communication Delays
}

\author{
Anh-Tuan Tran $\mathbb{D}^{1},{ }^{1}$ Bui Le Ngoc Minh, ${ }^{2,3}$ Phong Thanh Tran, ${ }^{1}$ Van Van Huynh $\mathbb{D}^{\mathbb{D}},{ }^{1}$ \\ Van-Duc Phan $\left(\mathbb{1},{ }^{4}\right.$ Viet-Thanh Pham, ${ }^{1}$ and Tam Minh Nguyen ${ }^{2}$ \\ ${ }^{1}$ Modeling Evolutionary Algorithms Simulation and Artificial Intelligence, Faculty of Electrical \& Electronics Engineering, \\ Ton Duc Thang University, Ho Chi Minh City, Vietnam \\ ${ }^{2}$ Faculty of Electrical and Electronics Engineering, Ho Chi Minh City University of Technology and Education, \\ Ho Chi Minh City, Vietnam \\ ${ }^{3}$ Faculty of Industrial Engineering, Tien Giang University, Mỹ Tho, Tien Giang Province 840000, Vietnam \\ ${ }^{4}$ Faculty of Automobile Technology, Van Lang University, Ho Chi Minh City, Vietnam \\ Correspondence should be addressed to Van Van Huynh; huynhvanvan@tdtu.edu.vn
}

Received 7 January 2021; Revised 12 February 2021; Accepted 10 March 2021; Published 22 March 2021

Academic Editor: Rui Wang

Copyright (c) 2021 Anh-Tuan Tran et al. This is an open access article distributed under the Creative Commons Attribution License, which permits unrestricted use, distribution, and reproduction in any medium, provided the original work is properly cited.

\begin{abstract}
Nowadays, the power systems are getting more and more complicated because of the delays introduced by the communication networks. The existence of the delays usually leads to the degradation and/or instability of power system performance. On account of this point, the traditional load frequency control (LFC) approach for power system sketches a destabilizing impact and an unacceptable system performance. Therefore, this paper proposes a new LFC based on adaptive integral second-order sliding mode control (AISOSMC) approach for the large-scale power system with communication delays (LSPSwCD). First, a new linear matrix inequality is derived to ensure the stability of whole power systems using Lyapunov stability theory. Second, an AISOSMC law is designed to ensure the finite time reachability of the system states. To the best of our knowledge, this is the first time the AISOSMC is designed for LFC of the LSPSwCD. In addition, the report of testing results presents that the suggested LFC based on AISOSMC can not only decrease effectively the frequency variation but also make successfully less in mount of power oscillation/ fluctuation in tie-line exchange.
\end{abstract}

\section{Introduction}

In modern power networks, the frequency stability is one of the significant problems related to the large-scale power system (LSPS) with communication delays. The system has been more and more complicated for LFC due to matched or mismatched uncertainties, load variations, and time-delays [1-4]. Communications time-delay is necessary in the LSPS; it cannot ignore and remove in the practical LSPS. So, the time-delay must consider in the area control error (ACE) signal. Normally, the time-delay can appear in the state variables or in the input channel of LSPS. The input control signal is transported to the power plants through communication networks with delay time. The state delay-time is the essential reason to effect on delaying the basic elements of communication or transportation in the LSPS. The deviation of tie-line exchange power and frequency are combined and known as an ACE to confirm the control frequency aim for the LSPS. The balance in both the tie-line and frequency exchange power is assured when an ACE is controlled and limited. In the LSPS model, the time-delay of ACE from regulation station to control area of the system is important [4-6]. Moreover, the time-delay is known as time lag in the power system model. That is, a big challenge to 
design the control algorithm to deal with the time-delay in the LSPS. In ACE control signal, the time lag may occur and lead to oscillation and instability in the LSPS [6-9]. Therefore, it is absolutely necessary to consider and explore the LFC for the LSPSwCD. The main objectives of LFC for each control area are continuing to keep the nominal value of the system frequency in range of the standard value and to act in accordance with the scheduled active power interchange with neighboring control areas.

In general, the previous LFC scheme such as PID control has been used to maintain tie-line power and frequency at schedule value which is one of the simplest controllers [10-13]. A suitable design of PID controller which is constructed on the direct synthesis method in frequency domain is given in [10]. In [11], a fractional-order PID control approach is built for the single-area LFC model using the Kharitonov's theorem to eliminate steady state error. Robust PID controller-based stability boundary locus and Kharitonov's theorem were used for LFC of the LSPS [12]. In [13], an ant lion algorithm is combined with PID to optimize the LFC loop parameters for improving the frequency regulation. The above approaches are suitable for application to design LFC of power network with nominal parameter and no uncertainty. However, the practical power network is always influenced or touched by an external factor of the uncertainties such as different load disturbances, which effect on the stability of power network. In order to overcome drawbacks and resolve the LFC problem effectively, advanced control techniques are developed for LFC design consisting of neural network and fuzzy control [14-16]. In [14], the LFC scheme for the LSPS was established and constructed on the adaptive fuzzy control method. A novel fuzzy PID control strategy with the fractional-order integrator and filtered derivative action was suggested to resolve automatic generation control for the power network [15]. In [16], the optimized operation of LFC is proposed for the LSPS with hybrid energy storage system.

On the other hand, as a powerful robust control strategy, SMC has been successfully applied to a wide variety of practical systems [17-19]. The terminal SMC is designed for LFC with the renewable power networks [20]. In [21], the adaptive double integral SMC is proposed for LFC of the LSPS where the time-delay is not considered. The goal of Sarkar was to design an adaptive integral higher order SMC for LFC problems to guarantee the frequency variation [22]. In [23], this article indicated nonlinear SMC with parametric uncertainties for LFC utilization in the LSPS to vary the system damping characteristics under uncertainties and step load disturbances. The approach given in [24] developed the strategy of SMC by model order-reduction of the LFC approach of the microhydropower system. A new full order SMC scheme in the paper [25] is utilized to eliminate and avoid the singularity of derivative of terms with fractional power elements. A novel adaptive SMC method has been used and developed for the LFC of the LSPS [26]. The proportional and integral switching surface was established for LFC of LSPS where the chattering problem is existed due to first-order SMC used [27]. The SMC-based LFC of above approaches can reduce the tie-line power and frequency deviations to ensure the stability of power network. However, the performance of LSPS using control scheme given in [20-27] is achieved without considering the time-delay in the power grids. In addition, the existence of the delays usually leads to the degradation and/or instability of power network performance. In order to solve this problem, the control scheme given in [28-30] is proposed to regulate the frequency deviation of the LSPS in the presence of communication delays and sudden load change. In [31], the LFC of the LSPS with nonlinear perturbations and time-varying delays are proposed using SMC. In [32], the sliding mode LFC is designed for the LSPS with time-delay and load disturbance. The sliding mode LFC strategy is suggested for the LSPS with time-delay and significant wind power penetration [33]. However, these SMC approaches are developed based on first-order time derivative [31-33]. In addition, the first-order SMC provides low accuracies due to chattering phenomenon in the control input. Therefore, in this paper, the second-order SMC is proposed to solve this problem. Moreover, an adaptive control method is adopted to estimate the unknown upper bound of aggregated uncertainties. To the best of our knowledge, the adaptive integral second-order sliding mode control (AISOSMC) scheme has not been developed for LFC problem in the LSPSwCD so far. The major contributions of this paper are displayed as follows:

The novel theory based on AISOSMC approach is offered for the LSPSwCD

The continuous control law is developed to deal with the influence of time-delay related to ACE on the LFC problem of the LSPSwCD

A state feedback controller containing both present and delayed state information is designed to improve tolerable delay margin of the LSPSwCD

A new LMI is established for proving the stability of whole PSPS based on Lyapunov stability theory

The proposed LFC based on AISOSMC can not only decrease effectively the frequency variation but also make successfully less in mount of power oscillation/ fluctuation in tie-line exchange

\section{Mathematical Model of a Large-Scale Power System with Communication Delays (LSPSwCD)}

In this part, we model the LSPSwCD. Figure 1 is the block diagram of the $i^{\text {th }}$ area of the LSPS with communication delay [28-30]. The model of the $i^{\text {th }}$ area system is composed of a governor, a nonreheat turbine, and a generator. The output of the generator is the frequency error. The tie-line power error is linearly proportional to the integration of frequency error. The linear combination of frequency error and the tie-line power error is the area control error (ACE). In addition, the time-delay of ACE signal is considered in the power network.

Nevertheless, when the load variation with minor change occurs during its conventional process, then the 


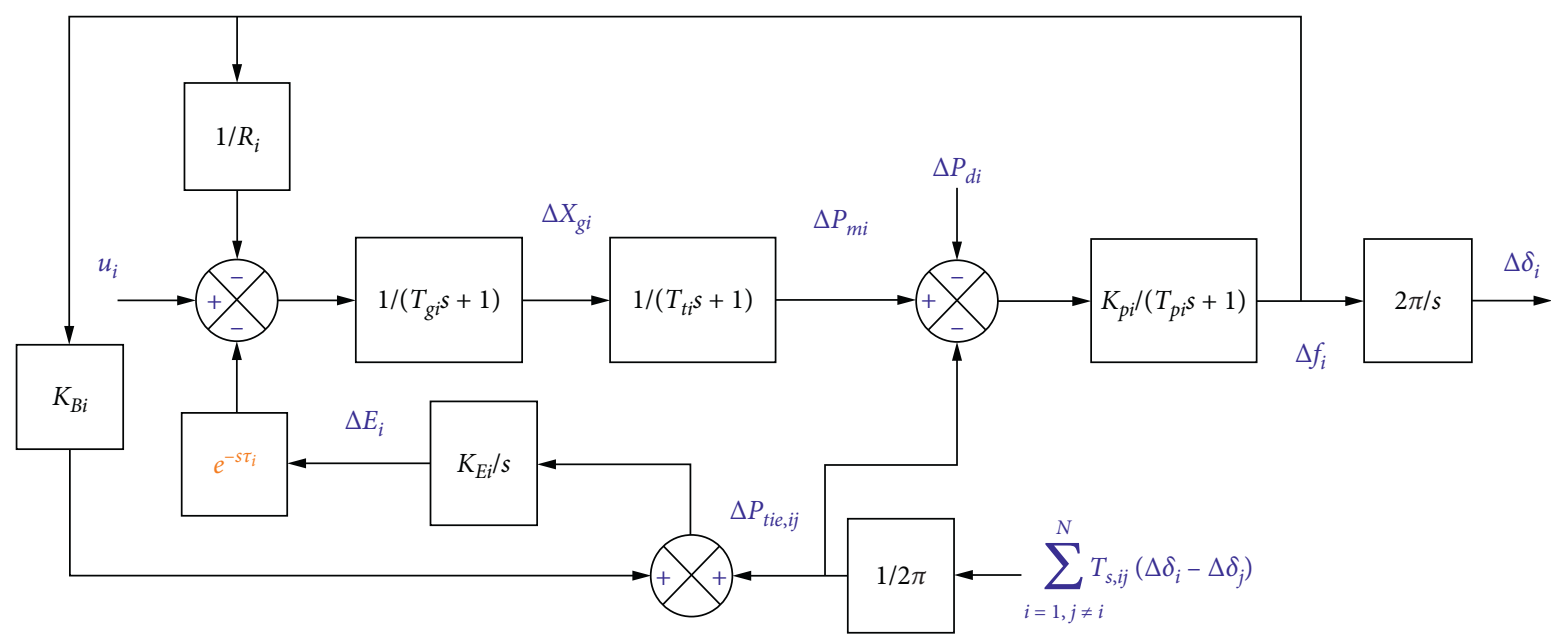

FIgURE 1: The structure of $i^{\text {th }}$ area of the LSPSwCD.

mathematical model of power network can be linearized near the stable operating point. Therefore, the dynamic equations of the above $i^{\text {th }}$ area system are expressed as follows:

$$
\begin{aligned}
\Delta \dot{f}_{i}(t) & =-\frac{1}{T_{p i}} \Delta f_{i}(t)+\frac{K_{P i}}{T_{p i}} \Delta P_{m i}(t)-\frac{K_{P i}}{T_{p i}} \Delta P_{d i}(t)-\frac{K_{P i}}{2 \pi T_{p i}} \sum_{i=1, j \neq i}^{N} T_{s, i j}\left[\Delta \delta_{i}(t)-\Delta \delta_{j}(t)\right] \\
\Delta \dot{P}_{m i}(t) & =-\frac{1}{T_{t i}} \Delta P_{m i}(t)+\frac{1}{T_{t i}} \Delta X_{g i}(t), \\
\Delta \dot{X}_{g i}(t) & =-\frac{1}{T_{g i} R_{i}} \Delta f_{i}(t)-\frac{1}{T_{g i}} \Delta X_{g i}(t)-\frac{1}{T_{g i}} \Delta E_{i}\left(t-\tau_{i}\right)+\frac{1}{T_{g i}} u_{i}(t), \\
\Delta \dot{E}_{i}(t) & =K_{B i} K_{E i} \Delta f_{i}(t)+\frac{K_{E i}}{2 \pi} \sum_{i=1, j \neq i}^{N} T_{s, i j}\left[\Delta \delta_{i}(t)-\Delta \delta_{j}(t)\right] \\
\Delta \dot{\delta}_{i}(t) & =2 \pi \Delta f_{i}(t),
\end{aligned}
$$

with $i=1$ to $N$ and $N$ is denoted as the number of areas, where $\Delta f_{i}(t)$ and $\Delta f_{j}(t)$ are the frequency variation of the $i^{\text {th }}$ area and the $j^{\text {th }}$ area, $\Delta P_{m i}(t)$ is the variation in governor output command, $\Delta X_{g i}(t)$ is the governor valve position of each area, $\Delta \delta_{i}(t)$ and $\Delta \delta_{j}(t)$ are the changes of rotor angle deviations of the $i^{\text {th }}$ area and the $j^{\text {th }}$ area, $\Delta P_{d i}(t)$ is the incremental change in local load of each area, $T_{s, i j}$ is the tieline power coefficient between the $i^{\text {th }}$ area and the $j^{\text {th }}$ area, $T_{g i}$ is the time constant of governor, $T_{t i}$ is the turbine time constant, and $T_{p i}$ is the time constant in power network, respectively. $K_{p i}, R_{i}, K_{E i}$, and $K_{B i}$ are power network gain, droop coefficient of individual area, speed regulation coefficient, and frequency bias factor. $\Delta E_{i}\left(t-\tau_{i}\right)$ is the area control error with the time-delay and $u_{i}(t)$ is the control input.

In state-space form, the system state variables are used as

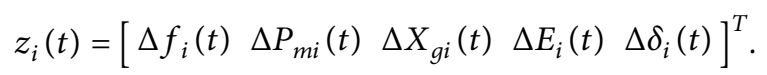

So, the LSPSwCD described by Figure 1 can be written and expressed in state-space representation as follows:

$$
\begin{aligned}
\dot{z}_{i}(t)= & A_{i} z_{i}(t)+D_{i} z_{i}\left(t-\tau_{i}\right)+B_{i} u_{i}(t) \\
& +\sum_{j=1 ; j \neq i}^{N} H_{i j} z_{j}(t)+F_{i} \Delta P_{d i}(t),
\end{aligned}
$$

where $i=1,2, \ldots, N$ and $N$ is denoted as the number of areas.

The state-space matrix $A_{i}, B_{i}, D_{i}, F_{i}, H_{i j}$ in mathematical model is given as follows: 


$$
\begin{aligned}
& A_{i}=\left[\begin{array}{cccccc}
\frac{-1}{T_{P i}} & \frac{K_{P i}}{T_{P i}} & 0 & 0 & -\frac{K_{P i}}{2 \pi T_{P i}} \sum_{i=1, j \neq i}^{N} T_{s, i j} \\
0 & -\frac{1}{T_{T i}} & \frac{1}{T_{T i}} & 0 & 0 \\
-\frac{1}{R_{i} T_{G i}} & 0 & -\frac{1}{T_{G i}} & 0 & 0 \\
K_{B i} K_{E i} & 0 & 0 & 0 & \frac{K_{E i}}{2 \pi} \sum_{i=1, j \neq i}^{N} T_{s, i j} \\
2 \pi & 0 & 0 & 0 & 0
\end{array}\right], \\
& D_{i}=\left[\begin{array}{ccccc}
0 & 0 & 0 & 0 & 0 \\
0 & 0 & 0 & 0 & 0 \\
0 & 0 & 0 & -\frac{1}{T_{G i}} & 0 \\
0 & 0 & 0 & 0 & 0 \\
0 & 0 & 0 & 0 & 0
\end{array}\right] \text {, }
\end{aligned}
$$

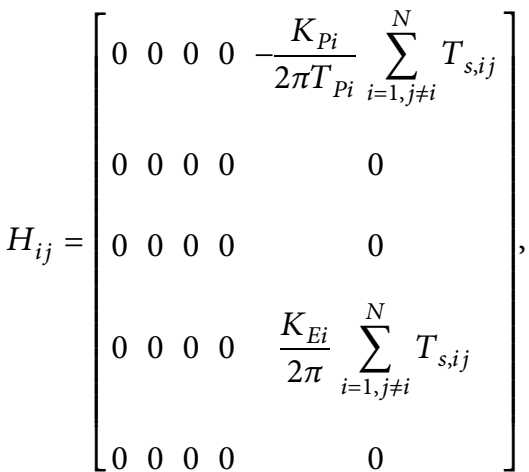

$$
\begin{aligned}
& B_{i}=\left[\begin{array}{c}
0 \\
0 \\
\frac{1}{T_{G i}} \\
0 \\
0
\end{array}\right] \text {; } \\
& F_{i}=\left[\begin{array}{c}
-\frac{K_{P i}}{T_{P i}} \\
0 \\
0 \\
0 \\
0
\end{array}\right] \text {. }
\end{aligned}
$$


In applied LSPSWCD, the operating point fluctuates continually induced by the fluctuating resource and load disturbance. In addition, by considering CDs element, the dynamic model of LSPSwCD with the uncertainties and parameter variations in equation (3) are further redefined as

$$
\begin{aligned}
\dot{z}_{i}(t)= & {\left[A_{i}+\Delta A_{i}\left(z_{i}, t\right)\right] z_{i}(t)+\left[D_{i}+\Delta D_{i}\left(z_{i}, t-\tau_{i}\right)\right] z_{i}\left(t-\tau_{i}\right)+B_{i}\left[u_{i}(t)+\xi_{i}\left(z_{i}, t\right)\right] } \\
& +\sum_{j=1 ; j \neq i}^{N}\left[H_{i j}+\Delta H_{i j}\left(z_{j}, t\right)\right] z_{j}(t)+F_{i} \Delta P_{d i}(t) \\
= & A_{i} z_{i}(t)+D_{i} z_{i}\left(t-\tau_{i}\right)+B_{i} u_{i}(t)+\sum_{j=1 ; j \neq i}^{N} H_{i j} z_{j}(t)+w_{i}\left(z_{i}, t\right),
\end{aligned}
$$

where $A_{i}, D_{i}, B_{i}$, and $H_{i j}$ are the system matrices with nominal value, $\Delta A_{i}\left(z_{i}, t\right), \Delta H_{i j}\left(z_{j}, t\right)$, and $\Delta D_{i}\left(z_{i}, t-\tau_{i}\right)$ are the parameter uncertainties, and $B_{i} \xi_{i}\left(z_{i}, t\right)$ is the disturbance input signal. The lumped uncertainty $w_{i}\left(z_{i}, t\right)$ is defined as follows:

$$
\begin{aligned}
w_{i}\left(z_{i}, t\right)= & \Delta A_{i}\left(z_{i}, t\right) z_{i}(t)+\Delta D_{i}\left(z_{i}, t-\tau_{i}\right) z_{i}\left(t-\tau_{i}\right) \\
& +B_{i} \xi_{i}\left(z_{i}, t\right)+\sum_{i=1 ; j \neq i}^{N} \Delta H_{i j} z_{j}(t)+F_{i} \Delta P_{d i}(t) .
\end{aligned}
$$

Assumption 1. The lumped uncertainties $w_{i}\left(z_{i}, t\right)$ and the differential of $\dot{w}_{i}\left(z_{i}, t\right)$ are bounded, i.e., there exist known scalars $\gamma_{i}$ and $\partial_{i}$ such that $\left\|w_{i}\left(z_{i}, t\right)\right\| \leq \gamma_{i}$ and $\left\|\dot{w}_{i}\left(z_{i}, t\right)\right\| \leq \partial_{i}$, where $\|$.$\| is the matrix norm.$

Assumption 2. The time-delay state vector must satisfy the condition $\left\|z_{i}\left(t-\tau_{i}\right)\right\| \leq z_{i \max }, z_{i \max }=\max \left\|z_{i \max }\right\|$, where $\|$. is the matrix norm. lemmas.

In order to prove the system stability, we recall some

Lemma 1 (see [34]). Let $\mathbf{X}$ and $\mathbf{Y}$ be actual matrices with appropriate dimension, then, for any scalar $\mu>0$, the sequent matrix inequality obtains

$$
\mathbf{X}^{\mathrm{T}} \mathbf{Y}+\mathbf{Y}^{\mathrm{T}} \mathbf{X} \leq \mu \mathbf{X}^{\mathrm{T}} \mathbf{X}+\mu^{-1} \mathbf{Y}^{\mathrm{T}} \mathbf{Y} .
$$

Lemma 2 (see [35]). ie following matrix inequality

$$
\left[\begin{array}{cc}
P(z) & \Gamma(z) \\
\Gamma^{T}(z) & Q(z)
\end{array}\right]>0
$$

where $P(z)=P^{T}(z), Q(z)=Q^{T}(z), \Gamma(z)$ depends affinely on $z$, is equivalent to $Q(z)>0$ and $P(z)-\Gamma$ $(z) Q^{-1}(z) \Gamma^{T}(z)>0$.
Lemma 3 (see [35]). Assume that $x \in R^{n}, y \in R^{n}, \mathbf{N} \in R^{n \times n}$, and $\mathbf{N}$ is the positive definite matrix. Then, the inequality

$$
x^{T} \mathbf{N} y+y^{T} \mathbf{N} x \leq \frac{1}{\varepsilon} x^{T} \mathbf{N} x+\varepsilon y^{T} \mathbf{N} y,
$$

holds for all $\varepsilon>0$.

\section{Adaptive Integral Second-Order Sliding Mode Control (AISOSMC) Design for LFC of Large- Scale Power System with Communication Delays (LSPSwCD)}

In this section, the AISOSMC method is developed for LFC of the LSPSwCD under mismatched parameter uncertainties and load disturbances. To solve this problem, we work step by step to design and implement the new controller approach. Firstly, the integral sliding surface (ISS) is represented for LSPSwCD to assure that the whole system is asymptotically stable. Secondly, the decentralized adaptive integral second-order sliding mode control law (DAISOSMCL) is designed to force the system trajectories to the sliding manifold and keep it there for after.

3.1. Stability Analysis of a LSPSwCD in Sliding Mode Dynamics. In detail, we first begin to propose and build an ISS for a LSPS:

$$
\sigma_{i}\left[z_{i}(t)\right]=E_{i} z_{i}(t)-\int_{0}^{t} E_{i}\left(A_{i}-B_{i} T_{i}\right) z_{i}(\tau) \mathrm{d} \tau,
$$

where $E_{i}$ is the constant matrix and $T_{i}$ is the design matrix, matrix $E_{i}$ is designed to guarantee that matrix $E_{i} B_{i}$ is nonsingular and matrix $T_{i}$ is chosen via pole assignment such that the eigenvalues of matrix $\left(A_{i}-B_{i} T_{i}\right)$ are always less than zero.

If we recognize and differentiate $\sigma_{i}\left[z_{i}(t)\right]$ with respect to time combined with (3), then

$$
\dot{\sigma}_{i}\left[z_{i}(t)\right]=E_{i}\left[A_{i} z_{i}(t)+D_{i} z_{i}\left(t-\tau_{i}\right)+B_{i} u_{i}(t)+\sum_{j=1 ; j \neq i}^{N} H_{i j} z_{j}(t)+w_{i}\left(z_{i}, t\right)\right]-E_{i}\left(A_{i}-B_{i} T_{i}\right) z_{i}(t) .
$$


So, the setting $\sigma_{i}\left[z_{i}(t)\right]=\dot{\sigma}_{i}\left[z_{i}(t)\right]=0$; the equivalent control is rewritten by

$$
\begin{aligned}
u_{i}^{\mathrm{eq}}(t)= & -\left(E_{i} B_{i}\right)^{-1}\left[E_{i} A_{i} z_{i}(t)+E_{i} D_{i} z_{i}\left(t-\tau_{i}\right)+\sum_{j=1 ; j \neq i}^{N} E_{i} H_{i j} z_{j}(t)+E_{i} w_{i}\left(z_{i}, t\right)\right] \\
& -\left[E_{i}\left(A_{i}-B_{i} T_{i}\right) z_{i}(t)\right] .
\end{aligned}
$$

Substituting $u_{i}(t)$ with $u_{i}^{\text {eq }}(t)$ into the LSPSwCD yields the sliding motion:

$$
\begin{aligned}
\dot{z}_{i}(t)= & \left(A_{i}-B_{i} T_{i}\right) z_{i}(t)+\left[I-B_{i}\left(E_{i} B_{i}\right)^{-1} E_{i}\right] D_{i} z_{i}\left(t-\tau_{i}\right)+\sum_{j=1 ; j \neq i}^{N}\left[I-B_{i}\left(E_{i} B_{i}\right)^{-1} E_{i}\right] H_{i j} z_{j}(t) \\
& +\left[I-B_{i}\left(E_{i} B_{i}\right)^{-1} E_{i}\right] w_{i}\left(z_{i}, t\right) .
\end{aligned}
$$

The introduction of the following theorem makes a condition that the AISOSMC dynamic equation (11) is asymptotically stable.
Theorem 1. The sliding motion (13) is asymptotically stable if and only if there includes symmetric positive definite matrix $Q_{i}, P_{i}, i=1,2, \ldots, N$, and positive scalars $q, \varphi_{i}$. and $\beta_{j}$ such that the following LMIs hold:

$$
\left[\begin{array}{cccc}
\Omega_{i}+\sum_{\substack{j=1 \\
j \neq i}}^{N} \beta_{j}^{-1} H_{j i}^{T} H_{j i} & 0 & D_{i}^{T}\left[I-B_{i}\left(E_{i} B_{i}\right)^{-1} E_{i}\right]^{T} & Q_{i}\left[I-B_{i}\left(E_{i} B_{i}\right)^{-1} E_{i}\right] \\
0 & -P_{i} & 0 & 0 \\
{\left[I-B_{i}\left(E_{i} B_{i}\right)^{-1} E_{i}\right] D_{i}} & 0 & -q Q_{i}^{-1} & 0 \\
{\left[I-B_{i}\left(E_{i} B_{i}\right)^{-1} E_{i}\right]^{T} Q_{i}} & 0 & 0 & -\varphi_{i}^{-1}
\end{array}\right]<0,
$$

where $\Omega_{i}=\left(A_{i}-B_{i} T_{i}\right)^{T} Q_{i}+Q_{i}\left(A_{i}-B_{i} T_{i}\right)+Q_{i}+P_{i}$.

Proof. To study and analyze stability of the sliding motion (13), we use the Lyapunov function as follows:

$$
V=\sum_{i=1}^{N}\left[z_{i}^{T}(t) Q_{i} z_{i}(t)+\int_{t-\tau_{i}}^{t} z_{i}^{T}(s) P_{i} z_{i}(s) \mathrm{d} s\right],
$$

where $Q_{i}, P_{i}>0$ satisfies (14). Then, taking the time derivative of (15) and using equation (13), we obtain

$$
\begin{aligned}
\dot{V}= & \sum_{i=1}^{N}\left\{\left[z_{i}^{T}(t)\left[\left(A_{i}-B_{i} T_{i}\right)^{T} Q_{i}+Q_{i}\left(A_{i}-B_{i} T_{i}\right)\right] z_{i}(t)\right.\right. \\
& +z_{i}^{T}\left(t-\tau_{i}\right) D_{i}^{T}\left[I-B_{i}\left(E_{i} B_{i}\right)^{-1} E_{i}\right]^{T} Q_{i} z_{i}(t)+z_{i}^{T}(t) Q_{i}\left[I-B_{i}\left(E_{i} B_{i}\right)^{-1} E_{i}\right] D_{i} z_{i}\left(t-\tau_{i}\right) \\
& +\sum_{j=1 ; j \neq i}^{N} z_{j}^{T}(t) H_{i j}^{T}\left[I-B_{i}\left(E_{i} B_{i}\right)^{-1} E_{i}\right]^{T} Q_{i} z_{i}(t)+\sum_{j=1 ; j \neq i}^{N} z_{i}^{T}(t) Q_{i}\left[I-B_{i}\left(E_{i} B_{i}\right)^{-1} E_{i}\right] H_{i j} z_{j}(t) \\
& \left.+w_{i}^{T}\left(z_{i}, t\right)\left[I-B_{i}\left(E_{i} B_{i}\right)^{-1} E_{i}\right]^{T} Q_{i} z_{i}(t)+z_{i}^{T}(t) Q_{i}\left[I-B_{i}\left(E_{i} B_{i}\right)^{-1} E_{i}\right] w_{i}\left(z_{i}, t\right)\right] \\
& \left.+z_{i}^{T}(t) P_{i} z_{i}(t)-z_{i}^{T}\left(t-\tau_{i}\right) P_{i} z_{i}\left(t-\tau_{i}\right)\right\} .
\end{aligned}
$$


To apply Lemma 1 in equation (16), we obtain

$$
\begin{aligned}
\dot{V} \leq & \sum_{i=1}^{N}\left\{z_{i}^{T}(t)\left[\left(A_{i}-B_{i} T_{i}\right)^{T} Q_{i}+Q_{i}\left(A_{i}-B_{i} T_{i}\right)\right] z_{i}(t)\right. \\
& +z_{i}^{T}\left(t-\tau_{i}\right) D_{i}^{t}\left[I-B_{i}\left(E_{i} B_{i}\right)^{-1} E_{i}\right]^{T} Q_{i} z_{i}(t)+z_{i}^{T}(t) Q_{i}\left[I-B_{i}\left(E_{i} B_{i}\right)^{-1} E_{i}\right] D_{i} z_{i}\left(t-\tau_{i}\right) \\
& +\sum_{j=1 ; j \neq i}^{N} z_{i}^{T}(t) \beta_{i}^{-1} Q_{i}\left[I-B_{i}\left(E_{i} B_{i}\right)^{-1} E_{i}\right]\left[I-B_{i}\left(E_{i} B_{i}\right)^{-1} E_{i}\right]^{T} Q_{i} z_{i}(t) \\
& +\sum_{j=1 ; j \neq i}^{N} z_{j}^{T}(t) \beta_{i} H_{i j}^{T} H_{i j} z_{j}(t)+z_{i}^{T}(t) P_{i} z_{i}(t)-z_{i}^{T}\left(t-\tau_{i}\right) P_{i} z_{i}\left(t-\tau_{i}\right) \\
& \left.+\chi_{i}^{-1} z_{i}^{T}(t) Q_{i}\left[I-B_{i}\left(E_{i} B_{i}\right)^{-1} E_{i}\right]\left[I-B_{i}\left(E_{i} B_{i}\right)^{-1} E_{i}\right]^{T} Q_{i} z_{i}(t)+\chi_{i} w_{i}^{T}\left(z_{i}, t\right) w_{i}\left(z_{i}, t\right)\right\} .
\end{aligned}
$$

Using Lemma 3 and equation (17), we get

$$
\begin{aligned}
\dot{V} \leq & \sum_{i=1}^{N}\left\{z_{i}^{T}(t)\left[\left(A_{i}-B_{i} T_{i}\right)^{T} Q_{i}+Q_{i}\left(A_{i}-B_{i} T_{i}\right)\right] z_{i}(t)\right. \\
& +z_{i}^{T}\left(t-\tau_{i}\right) D_{i}^{T}\left[I-B_{i}\left(E_{i} B_{i}\right)^{-1} E_{i}\right]^{T} Q_{i}\left[I-B_{i}\left(E_{i} B_{i}\right)^{-1} E_{i}\right] D_{i} z_{i}\left(t-\tau_{i}\right)+z_{i}^{T}(t) Q_{i} z_{i}(t) \\
& +\sum_{j=1 ; j \neq i}^{N} z_{i}^{T}(t) \beta_{i}^{-1} Q_{i}\left[I-B_{i}\left(E_{i} B_{i}\right)^{-1} E_{i}\right]\left[I-B_{i}\left(E_{i} B_{i}\right)^{-1} E_{i}\right]^{T} Q_{i} z_{i}(t) \\
& +\sum_{j=1 ; j \neq i}^{N} z_{j}^{T}(t) \beta_{i} H_{i j}^{T} H_{i j} z_{j}(t)+z_{i}^{T}(t) P_{i} z_{i}(t)-z_{i}^{T}\left(t-\tau_{i}\right) P_{i} z_{i}\left(t-\tau_{i}\right) \\
& \left.+\chi_{i}^{-1} z_{i}^{T}(t) Q_{i}\left[I-B_{i}\left(E_{i} B_{i}\right)^{-1} E_{i}\right]\left[I-B_{i}\left(E_{i} B_{i}\right)^{-1} E_{i}\right]^{T} Q_{i} z_{i}(t)+\chi_{i} w_{i}^{T}\left(z_{i}, t\right) w_{i}\left(z_{i}, t\right)\right\} .
\end{aligned}
$$

Since $\sum_{i=1}^{N} \sum_{j=1, j \neq i}^{N} z_{j}^{T}(t) \beta_{i}^{-1} H_{i j}^{T} H_{i j} z_{j}(t)=\sum_{i=1}^{N} \sum_{j=1, j \neq i}^{N}$ $z_{i}^{T}(t) \beta_{j}^{-1} H_{j i}^{T} H_{j i} z_{i}(t)$, we achieve that

$$
\begin{aligned}
\dot{V} \leq & \sum_{i=1}^{N}\left\{z _ { i } ^ { T } ( t ) \left[\left(A_{i}-B_{i} T_{i}\right)^{T} Q_{i}+Q_{i}\left(A_{i}-B_{i} T_{i}\right)+Q_{i}\right.\right. \\
& \left.+\varphi_{i} Q_{i}\left[I-B_{i}\left(E_{i} B_{i}\right)^{-1} E_{i}\right]\left[I-B_{i}\left(E_{i} B_{i}\right)^{-1} E_{i}\right]^{T} Q_{i}\right] z_{i}(t) \\
& +\sum_{j=1 ; j \neq i}^{N} z_{i}^{T}(t) \beta_{j} H_{j i}^{T} H_{j i} z_{i}(t)+\chi_{i} w_{i}^{T}\left(z_{i}, t\right) w_{i}\left(z_{i}, t\right) \\
& +z_{i}^{T}\left(t-\tau_{i}\right) D_{i}^{T}\left[I-B_{i}\left(E_{i} B_{i}\right)^{-1} E_{i}\right]^{T} Q_{i}\left[I-B_{i}\left(E_{i} B_{i}\right)^{-1} E_{i}\right] D_{i} z_{i}\left(t-\tau_{i}\right) \\
& \left.+z_{i}^{T}(t) P_{i} z_{i}(t)-z_{i}^{T}\left(t-\tau_{i}\right) P_{i} z_{i}\left(t-\tau_{i}\right)\right\},
\end{aligned}
$$

where $\varphi_{i}=\chi_{i}^{-1}+(N-1) \beta_{i}^{-1}$. 
The matrix $D_{i}^{T}\left[I-B_{i}\left(E_{i} B_{i}\right)^{-1} E_{i}\right]^{T} Q_{i}\left[I-B_{i}\left(E_{i} B_{i}\right)^{-1}\right.$ $\left.E_{i}\right] D_{i}$ is the semipositive definite. Since the $z_{i}(t)$ for $i=$
$1,2, \ldots, N$ are independent of each other. Then, from equation (32) of paper [36], the following is true:

$$
V\left(z_{1}\left(t-\tau_{1}\right), z_{2}\left(t-\tau_{2}\right), z_{3}\left(t-\tau_{3}\right), \ldots, z_{N}\left(t-\tau_{N}\right)\right) \leq q V\left(z_{1}(t), z_{2}(t), z_{3}(t), \ldots, z_{N}(t)\right)
$$

for $q>1$ is equivalent to

$$
\begin{aligned}
& \sum_{i=1}^{N}\left\{z_{i}^{T}\left(t-\tau_{i}\right) D_{i}^{T}\left[I-B_{i}\left(E_{i} B_{i}\right)^{-1} E_{i}\right]^{T} Q_{i}\left[I-B_{i}\left(E_{i} B_{i}\right)^{-1} E_{i}\right] D_{i} z_{i}\left(t-\tau_{i}\right)\right\} \\
& \leq q \sum_{i=1}^{N}\left\{z_{i}^{T}(t) D_{i}^{T}\left[I-B_{i}\left(E_{i} B_{i}\right)^{-1} E_{i}\right]^{T} Q_{i}\left[I-B_{i}\left(E_{i} B_{i}\right)^{-1} E_{i}\right] D_{i} z_{i}(t)\right\} .
\end{aligned}
$$

Then, we can get the following equation:

$$
\begin{aligned}
\dot{V} \leq & \sum_{i=1}^{N}\left\{z _ { i } ^ { T } ( t ) \left[\left(A_{i}-B_{i} T_{i}\right)^{T} Q_{i}+Q_{i}\left(A_{i}-B_{i} T_{i}\right)+Q_{i}+P_{i}\right.\right. \\
& +\varphi_{i} Q_{i}\left[I-B_{i}\left(E_{i} B_{i}\right)^{-1} E_{i}\right]\left[I-B_{i}\left(E_{i} B_{i}\right)^{-1} E_{i}\right]^{T} Q_{i} \\
& \left.+q D_{i}^{T}\left[I-B_{i}\left(E_{i} B_{i}\right)^{-1} E_{i}\right]^{T} Q_{i}\left[I-B_{i}\left(E_{i} B_{i}\right)^{-1} E_{i}\right] D_{i}\right] z_{i}(t) \\
& +\sum_{j=1 ; j \neq i}^{N} z_{i}^{T}(t) \beta_{j} H_{j i}^{T} H_{j i} z_{i}(t)-z_{i}^{T}\left(t-\tau_{i}\right) P_{i} z_{i}\left(t-\tau_{i}\right) \\
& \left.+\chi_{i} w_{i}^{T}\left(z_{i}, t\right) w_{i}\left(z_{i}, t\right)\right\} .
\end{aligned}
$$

Based on Assumption 1, the following equation can be achieved:

$$
\begin{aligned}
\dot{V} \leq & \sum_{i=1}^{N}\left\{z _ { i } ^ { T } ( t ) \left[\left(A_{i}-B_{i} T_{i}\right)^{T} Q_{i}+Q_{i}\left(A_{i}-B_{i} T_{i}\right)+Q_{i}+P_{i}\right.\right. \\
& +\varphi_{i} Q_{i}\left[I-B_{i}\left(E_{i} B_{i}\right)^{-1} E_{i}\right]\left[I-B_{i}\left(E_{i} B_{i}\right)^{-1} E_{i}\right]^{T} Q_{i} \\
& \left.+q D_{i}^{T}\left[I-B_{i}\left(E_{i} B_{i}\right)^{-1} E_{i}\right]^{T} Q_{i}\left[I-B_{i}\left(E_{i} B_{i}\right)^{-1} E_{i}\right] D_{i}\right] z_{i}(t) \\
& \left.+\sum_{j=1 ; j \neq i}^{N} z_{i}^{T}(t) \beta_{j} H_{j i}^{T} H_{j i} z_{i}(t)-z_{i}^{T}\left(t-\tau_{i}\right) P_{i} z_{i}\left(t-\tau_{i}\right)+\iota_{i}\right\},
\end{aligned}
$$

where $\iota_{i}=\chi_{i} \gamma_{i}^{2}$.

Define the augmented vector

$$
\begin{gathered}
\Psi_{i}(t)=\left[\begin{array}{ll}
z_{i}^{T}(t) & z_{i}^{T}\left(t-\tau_{i}\right)
\end{array}\right]^{T}, \\
\dot{V} \leq \Psi_{i}^{T}(t) \Theta_{i} \Psi_{i}(t)+\iota_{i} .
\end{gathered}
$$

From Lemma 2 and LMI (14), we get

$$
\Theta_{i}=-\left[\begin{array}{cc}
\Xi_{i} & 0 \\
0 & -P_{i}
\end{array}\right]>0
$$

where

$$
\begin{aligned}
\Xi_{i}= & \left(A_{i}-B_{i} T_{i}\right)^{T} Q_{i}+Q_{i}\left(A_{i}-B_{i} T_{i}\right)+Q_{i}+P_{i}+\varphi_{i} Q_{i}\left[I-B_{i}\left(E_{i} B_{i}\right)^{-1} E_{i}\right]\left[I-B_{i}\left(E_{i} B_{i}\right)^{-1} E_{i}\right]^{T} Q_{i} \\
& +q D_{i}^{T}\left[I-B_{i}\left(E_{i} B_{i}\right)^{-1} E_{i}\right]^{T} Q_{i}\left[I-B_{i}\left(E_{i} B_{i}\right)^{-1} E_{i}\right] D_{i}+\sum_{j=1, j \neq i}^{N} \beta_{j}^{-1} H_{j i}^{T} H_{j i} .
\end{aligned}
$$


According to equations (23) and (25), we obtain

$$
\dot{V} \leq \sum_{i=1}^{N}\left[-\lambda_{\min }\left(\Theta_{i}\right)\left\|\Psi_{i}(t)\right\|^{2}+\iota_{i}\right],
$$

where the constant value $t_{i}$ and the eigenvalue $\lambda_{\min }\left(\Theta_{i}\right)>0$. Therefore, $\dot{V}<0$ is achieved with $\left\|\Psi_{i}(t)\right\|>\sqrt{\left(\iota_{i} / \lambda_{\min }\left(\Theta_{i}\right)\right)}$. Hence, the sliding motion of system (13) is asymptotically stable.

Remark 1 . The adaptive integral second-order sliding mode control design is composed of the hitting phase and the sliding phase. The proposed controller is used to force the system state trajectories to sliding phase and keep the system state trajectories on it thereafter. If the disturbance and uncertainty satisfy the matching condition $\operatorname{rank}\left[B_{i}, w_{i}\right.$ $\left.\left(z_{i}, t\right)\right]=\operatorname{rank}\left[B_{i}\right]$, the system in the sliding mode is invariant to disturbance and uncertainty. The stability of system under matched condition is easier than mismatched condition. The proposed controller can compensate for disturbance and uncertainty directly under matched condition. Therefore, the stability of the system in the sliding mode under mismatched condition $\operatorname{rank}\left[B_{i}, w_{i}\right.$ $\left.\left(z_{i}, t\right)\right] \neq \operatorname{rank}\left[B_{i}\right]$ has been considered and proved using LMI technique based on Lyapunov stability theory.

3.2. First-Order SMC Design. In order to guarantee the reachability of state variables to the ISS (10), the decentralized first-order integral SMC law is designed as follows [18]:

$$
\begin{aligned}
u_{i}^{\mathrm{FOSMC}}(t)= & -\left(E_{i} B_{i}\right)^{-1}\left\{\left\|E_{i}\right\|\left\|B_{i}\right\|\left\|T_{i}\right\|\left\|z_{i}(t)\right\|+\left\|E_{i}\right\|\left\|D_{i}\right\|\left\|z_{i}\left(t-\tau_{i}\right)\right\|\right. \\
& \left.+\sum_{j=1 ; j \neq i}^{N}\left\|E_{j}\right\|\left\|H_{j i}\right\|\left\|z_{i}(t)\right\|+\left\|E_{i}\right\| \bar{\gamma}_{i}+\widetilde{\varepsilon}_{i} \operatorname{sat}\left\{\sigma_{i}\left[z_{i}(t)\right]\right\}\right\},
\end{aligned}
$$

where $\widetilde{\varepsilon}_{i}>0$ and

$$
\operatorname{sat}\left\{\sigma_{i}\left[z_{i}(t)\right]\right\}= \begin{cases}1, & \sigma_{i}\left[z_{i}(t)\right]>1, \\ \sigma_{i}\left[z_{i}(t)\right], & \text { When }-1 \leq \sigma_{i}\left[z_{i}(t)\right] \leq 1, \\ -1, & \sigma_{i}\left[z_{i}(t)\right]<-1 .\end{cases}
$$

Remark 2. The first-order SMC can be used to study LFC of power system under matched uncertainties. However, the parametric uncertainties not usually satisfy the matched condition in real power network. Consequently, some main constraints are necessary to design the first-order SMC to compensate the uncertainties, which can guarantee the convergence in nominal frequency and the system stability but the system trajectories cannot reach to origin point. Therefore, the second-order ISS has been used as the following part to force the system trajectory to equivalent point and to make better the transient performance.
3.3. Decentralized Adaptive Integral Second-Order Sliding Mode Control Law (DAISOSMCL) Design. In this step, the DAISOSMCL is developed for the LSPSwCD to reduce the frequency deviation. The main purpose of the proposed control scheme is to effect on the second-order derivative of the sliding variables $\sigma_{i}\left[z_{i}(t)\right]$. By using the discontinuous control signal $\dot{u}_{i}(t)$, it is simple to make $\sigma_{i}\left[z_{i}(t)\right]$ and $\dot{\sigma}_{i}\left[z_{i}(t)\right]$ converge to zero. So, the input control signal $u_{i}(t)$ of LSPSwCD can get by integrating the discontinuous signal $\dot{u}_{i}(t)$ to make continuous signal $u_{i}(t)$. Therefore, the DAISOSMCL approach removes some undesired frequency oscillations in the control signal of LSPSwCD.

We define and establish the sliding manifold (SMd) $G_{i}\left[z_{i}(t)\right]$ as

$$
\begin{aligned}
& G_{i}\left[z_{i}(t)\right]=\dot{\sigma}_{i}\left[z_{i}(t)\right]+\varepsilon_{i} \sigma\left[z_{i}(t)\right], \\
& \dot{G}_{i}\left[z_{i}(t)\right]=\ddot{\sigma}_{i}\left[z_{i}(t)\right]+\varepsilon_{i} \dot{\sigma}_{i}\left[z_{i}(t)\right],
\end{aligned}
$$

where $\varepsilon_{i}>0$ is a positive constant, according to equation (30); the equation (31) can be redefined as

$$
\begin{aligned}
\dot{G}_{i}\left[z_{i}(t)\right]= & E_{i}\left[A_{i} \dot{z}_{i}(t)+D_{i} \dot{z}_{i}\left(t-\tau_{i}\right)+B_{i} \dot{u}_{i}(t)+\sum_{j=1 ; j \neq i}^{N} H_{i j} \dot{z}_{j}(t)+\dot{w}_{i}\left(z_{i}, t\right)\right] \\
& -E_{i}\left(A_{i}-B_{i} T_{i}\right) \dot{z}_{i}(t)+\varepsilon_{i} \dot{\sigma}_{i}\left[z_{i}(t)\right] .
\end{aligned}
$$


Based on the definition of sliding surface and SMd, the where continuous DAISOSMCL for LFC of a LSPSwCD is given as follows:

$$
\dot{u}_{i}(t)=\dot{u}_{i}^{\mathrm{SOSMC}}(t)+\dot{u}_{i}^{\mathrm{adt}}(t)
$$

$$
\begin{gathered}
\dot{u}_{i}^{\text {SOSMC }}(t)=-\left(E_{i} B_{i}\right)^{-1}\left[\left\|E_{i}\right\|\left\|B_{i}\right\|\left\|T_{i}\right\|\left\|\dot{z}_{i}(t)\right\|+\left\|E_{i}\right\|\left\|D_{i}\right\|\left\|\dot{z}\left(t-\tau_{i}\right)\right\|+\sum_{j=1 ; j \neq i}^{N}\left\|E_{j}\right\|\left\|H_{j i}\right\|\left\|\dot{z}_{i}(t)\right\|\right. \\
\left.+\varepsilon_{i}\left\|\dot{\sigma}_{i}\left[z_{i}(t)\right]\right\|+\left\|E_{i}\right\| \partial_{i}+\bar{\varepsilon}_{i}\right] \frac{G_{i}\left[z_{i}(t)\right]}{\left\|G_{i}\left[z_{i}(t)\right]\right\|}, \\
\dot{u}_{i}^{\text {adt }}(t)=-\left(E_{i} B_{i}\right)^{-1} I\left[\widehat{\partial}_{i}(t)\left\|E_{i}\right\|+\bar{p}_{i} \frac{\partial_{i}^{2}}{4}\right], \quad i=1,2, \ldots, N,
\end{gathered}
$$

where

$$
\dot{\widehat{\partial}}_{i}(t)=p_{i}\left(-\bar{p}_{i} \widehat{\partial}_{i}(t)+\left\|E_{i}\right\|\right), \quad i=1,2, \ldots, N,
$$

in which $p_{i}$ and $\bar{p}_{i}$ are the positive constants.

Then, we have the main result which is presented as follows.

Theorem 2. Consider the closed loop of the power systems with the DAISOSMCL (33). Then, every solution trajectory of system state is directed towards the $S M d G_{i}\left[z_{i}(t)\right]$, and once the trajectory hits the SMd $G_{i}\left[z_{i}(t)\right]$, it remains on the sliding manifold thereafter.

Proof. The Lyapunov function is introduced as follows:

$$
\bar{V}(t)=\sum_{i=1}^{N}\left\{\left\|G_{i}\left[z_{i}(t)\right]\right\|+\frac{0.5}{p_{i}} \widetilde{\partial}_{i}^{2}\right\},
$$

where $\tilde{\partial}_{i}(t)=\partial_{i}-\widehat{\partial}_{i}(t)$.

So, taking the derivative of $\bar{V}(t)$, we have

$$
\begin{aligned}
\dot{\bar{V}}= & \sum_{i=1}^{N}\left[\frac{G_{i}^{T}\left[z_{i}(t)\right]}{\left\|G_{i}\left[z_{i}(t)\right]\right\|} \dot{G}_{i}\left[z_{i}(t)\right]-\tilde{\partial}_{i}(t) \frac{\dot{\widehat{\partial}}_{i}(t)}{p_{i}}\right] \\
= & \sum_{i=1}^{N} \frac{G_{i}^{T}\left[z_{i}(t)\right]}{\left\|G_{i}\left[z_{i}(t)\right]\right\|}\left\{E_{i}\left[A_{i} \dot{z}_{i}(t)+D_{i} \dot{z}\left(t-\tau_{i}\right)+B_{i} \dot{u}_{i}(t)+\sum_{\substack{j=1 \\
j \neq i}}^{N} H_{i j} \dot{z}_{j}(t)+\dot{w}_{i}\left(z_{i}, t\right)\right]\right. \\
& \left.-E_{i}\left(A_{i}-B_{i} T_{i}\right) \dot{z}_{i}(t)+\varepsilon_{i} \dot{\sigma}_{i}\left[z_{i}(t)\right]\right\}-\sum_{i=1}^{N} \tilde{\partial}_{i}(t) \frac{\dot{\widehat{\partial}}_{i}(t)}{p_{i}} .
\end{aligned}
$$

According to equation (37) and property $\|A B\| \leq\|A\|\|B\|$, we have 


$$
\begin{aligned}
\dot{\bar{V}}= & \sum_{i=1}^{N}\left\{E_{i}\left[A_{i} \dot{z}_{i}(t)+D_{i} \dot{z}\left(t-\tau_{i}\right)+B_{i} \dot{u}_{i}(t)+\sum_{\substack{j=1 \\
j \neq i}}^{N} H_{i j} \dot{z}_{j}(t)+\dot{w}_{i}\left(z_{i}, t\right)\right]\right\} \\
& +\sum_{i=1}^{N} \frac{G_{i}^{T}\left[z_{i}(t)\right]}{\left\|G_{i}\left[z_{i}(t)\right]\right\|} E_{i} B_{i} \dot{u}_{i}(t)-\sum_{i=1}^{N} \widetilde{\partial}_{i}(t) \frac{\dot{\vec{\partial}}_{i}(t)}{p_{i}} \\
\leq & \sum_{i=1}^{N}\left\{\left\|E_{i}\right\|\left\|B_{i}\right\|\left\|T_{i}\right\|\left\|\dot{z}_{i}(t)\right\|+\left\|E_{i}\right\|\left\|D_{i}\right\|\left\|\dot{z}_{i}\left(t-\tau_{i}\right)\right\|+\delta_{i}\left\|\dot{\sigma}_{i}\left[z_{i}(t)\right]\right\|\right. \\
& \left.+\sum_{\substack{j=1 \\
j \neq i}}^{N}\left\|E_{i}\right\|\left\|H_{i j}\right\|\left\|\dot{z}_{i}(t)\right\|+\left\|E_{i}\right\|\left\|\dot{w}_{i}\left(z_{i}, t\right)\right\|\right\}+\sum_{i=1}^{N} \frac{G_{i}^{T}\left[z_{i}(t)\right]}{\left\|G_{i}\left[z_{i}(t)\right]\right\|} E_{i} B_{i} \dot{u}_{i}(t)-\sum_{i=1}^{N} \widetilde{\partial}_{i}(t) \frac{\dot{\partial}_{i}(t)}{p_{i}} .
\end{aligned}
$$

Using Assumption 1, we achieve

$\dot{\bar{V}} \leq \sum_{i=1}^{N}\left\{\left\|E_{i}\right\|\left\|B_{i}\right\|\left\|T_{i}\right\|\left\|\dot{z}_{i}(t)\right\|+\left\|E_{i}\right\|\left\|D_{i}\right\|\left\|\dot{z}_{i}\left(t-\tau_{i}\right)\right\|+\left\|E_{i}\right\| \partial_{i}\right.$

$$
\begin{aligned}
& \left.+\sum_{\substack{j=1 \\
j \neq i}}^{N}\left\|E_{j}\right\|\left\|H_{j i}\right\|\left\|\dot{z}_{i}(t)\right\|+\varepsilon_{i}\left\|\dot{\sigma}_{i}\left[z_{i}(t)\right]\right\|\right\} \\
& +\sum_{i=1}^{N} \frac{G_{i}^{T}\left[z_{i}(t)\right]}{\left\|G_{i}\left[z_{i}(t)\right]\right\|} E_{i} B_{i} \dot{u}_{i}(t)-\sum_{i=1}^{N} \widetilde{\partial}_{i}(t) \frac{\dot{\vec{\partial}}_{i}(t)}{p_{i}} .
\end{aligned}
$$

$$
\begin{aligned}
\dot{\bar{V}} & \leq \sum_{i=1}^{N}\left[-\bar{\varepsilon}_{i}-\widehat{\partial}_{i}(t)\left\|E_{i}\right\|-\bar{p}_{i} \frac{\partial_{i}^{2}}{4}+\left\|E_{i}\right\| \partial_{i}\right]-\sum_{i=1}^{N}\left[\partial_{i}\left\|E_{i}\right\|\right]-\sum_{i=1}^{N}\left[\bar{p}_{i} \hat{\partial}_{i}^{2}(t)-\bar{p}_{i} \partial_{i} \widehat{\partial}_{i}(t)-\widehat{\partial}_{i}(t)\left\|E_{i}\right\|\right] \\
& =\sum_{i=1}^{N}\left(-\bar{\varepsilon}_{i}-\bar{p}_{i} \frac{\partial_{i}^{2}}{4}\right)-\sum_{i=1}^{N}\left[\bar{p}_{i} \widehat{\partial}_{i}^{2}(t)-\bar{p}_{i} \partial_{i} \widehat{\partial}_{i}(t)\right] \\
& =\sum_{i=1}^{N}\left[\left(-\bar{\varepsilon}_{i}-\bar{p}_{i} \frac{\partial_{i}^{2}}{4}\right)-\sum_{i=1}^{N}\left[\bar{p}_{i}\left(\widehat{\partial}_{I}(t)-\partial_{i}\right)^{2}-\bar{p}_{i} \frac{\partial_{i}^{2}}{4}\right]\right. \\
& =\sum_{i=1}^{N}-\bar{\varepsilon}_{i}-\sum_{i=1}^{N}\left[\bar{p}_{i}\left(\widehat{\partial}_{I}(t)-\partial_{i}\right)^{2}\right] .
\end{aligned}
$$

The above inequality implies that the system trajectories of the LSPSwCD (3) reach the SMd $G_{i}\left[z_{i}(t)\right]$ and keep it for later.
Using the DAISOSMCL (33) yields 
(10) indicates that the integral term $\int_{0}^{t} E_{i}\left(A_{i}-B_{i} T_{i}\right) z_{i}(\tau) \mathrm{d} \tau$ is only reflected in the proposed DAISOSMCL (33). Therefore, the control law (33) is to improve the performance of steady state error in comparison with the traditional integral SMC.

\section{Results and Discussion}

Based on the interconnected time-delay power network, the four cases are offered to prove the strength of the suggested AISOSMC approach under the required conditions such as the different load disturbances and the parameter variations. A LSPSwCD is analyzed to explain the robustness and effectiveness of the suggested AISOSMC approach. The parameters of LSPSwCD were given in [22] as shown Table 1.

Case 1. The presented LFC based on AISOSMC is used to compare with the traditional LFC approach under the same condition in [22]. The proposed LFC based on AISOSMC has been examined with different step load disturbance effect on the thermal power plant with nominal parameter conditions. We have considered the system parameters of matched uncertainties. In this case, the load disturbances are $\Delta P_{d 1}=0.02, \Delta P_{d 2}=0.015$, and $\Delta P_{d 3}=0.01$ (p.u.MW) at $t_{1}=0$ in three areas of the LSPS. The frequency deviations of $\Delta f_{1}, \Delta f_{2}$, and $\Delta f_{3}$ for the LSPS with delay-time as $\tau_{i}=0.1 \mathrm{~s}$ $(i=1,2,3)$ are displayed in Figures $2-4$ which are the tie-line power deviation and control input signal for three-area power networks. It is easy to realize that the transient responses achieved in the proposed LFC based on AISOSMC is faster in the settling time, but it has less magnitude of overshoot percentage with the proposed recent controller in [22].

Remark 4. Due to Figures 2 to 4, the testing simulation results in this part are appointed in Table 2. In particular, the report of results can show in an effective comparison while the time-delay communication is considered for the largescale power network. Therefore, the system performance of the suggested AISOSMC is well balanced, and frequency variation is zero after $1 \mathrm{~s}$.

Case 2. As the same matched parameter uncertainty of the three areas is used in [22], the cosine function around the nominal operation point is used to verify the usefulness and robustness of the suggested controller to load disturbance. The step load disturbances in LSPSwCD are chosen as $\Delta P_{d 1}=0.01$ p.u.MW at $t_{1}=0 \mathrm{~s}$ and $\Delta P_{d 2}=0.015$ p.u.MW at $t_{2}=0$ and $\Delta P_{d 3}=0.02$ p.u.MW at $t_{3}=0$.

$$
\Delta A_{1}=\left[\begin{array}{ccccc}
0 & 0 & 0 & 0 & 0 \\
0 & 0 & 0 & 0 & 0 \\
-2.26 \cos (t) & 2 \cos (t) & -2.604 \cos (t) & 3 \cos (t) & 0 \\
0 & 0 & 0 & 0 & 0 \\
0 & 0 & 0 & 0 & 0
\end{array}\right]
$$

and the matched uncertainty among subsystems are assumed the same as [22] and $\Delta A_{1}=\Delta A_{2}=\Delta A_{3}$.
TABLE 1: The parameters of three-area power system.

\begin{tabular}{lcccccccc}
\hline Areas & $T_{P i}$ & $K_{P i}$ & $T_{T i}$ & $T_{G i}$ & $R_{i}$ & $K_{E i}$ & $K_{B i}$ & $K_{i j}$ \\
\hline 1 & 20 & 120.0 & 0.30 & 0.080 & 2.4 & 10.0 & 0.41 & 0.550 \\
2 & 25 & 112.5 & 0.33 & 0.072 & 2.7 & 9.0 & 0.37 & 0.650 \\
3 & 20 & 115.0 & 0.35 & 0.070 & 2.5 & 7.1 & 0.40 & 0.545 \\
\hline
\end{tabular}

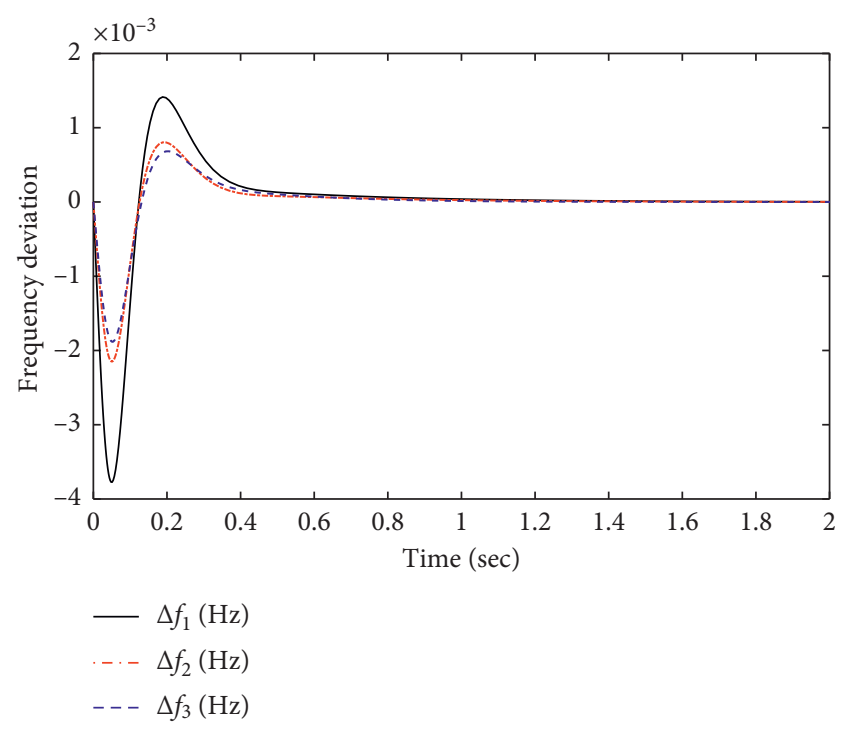

Figure 2: Frequency variation of the system.

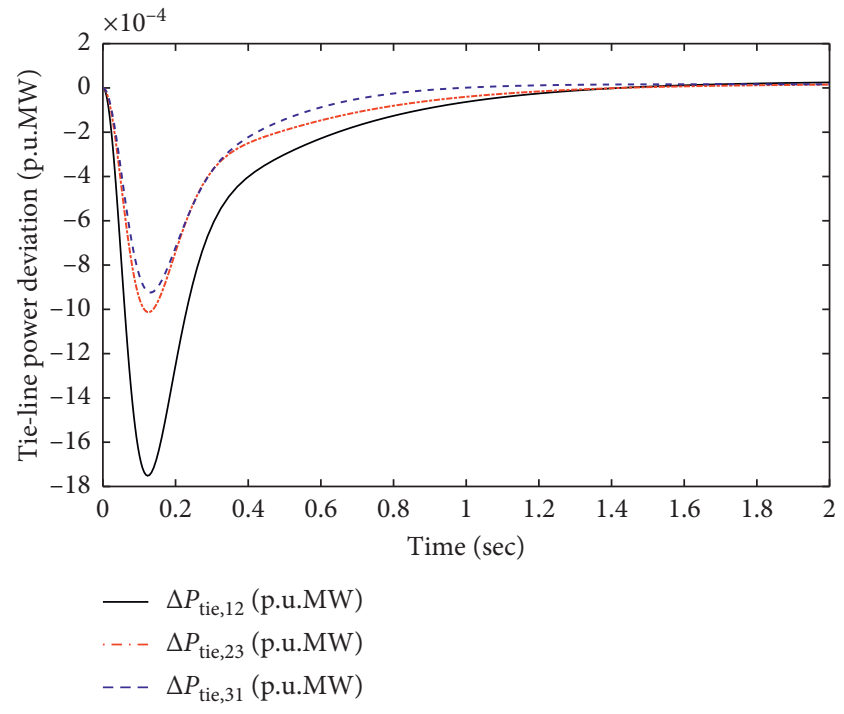

FIgURE 3: Tie-line variation of the system.

Figure 5 indicates that the proposed LFC based on AISOSMC to three areas with CDs, $\tau_{i}=0.1$; the frequency deviation reaching to zero is about $2 \mathrm{~s}$ much smaller than the comparative LFC used in [22] within $10 \mathrm{~s}$. Figure 6 plots the control signal of the system under matched uncertainty. The tie-line power variations of three areas with LFC based on 


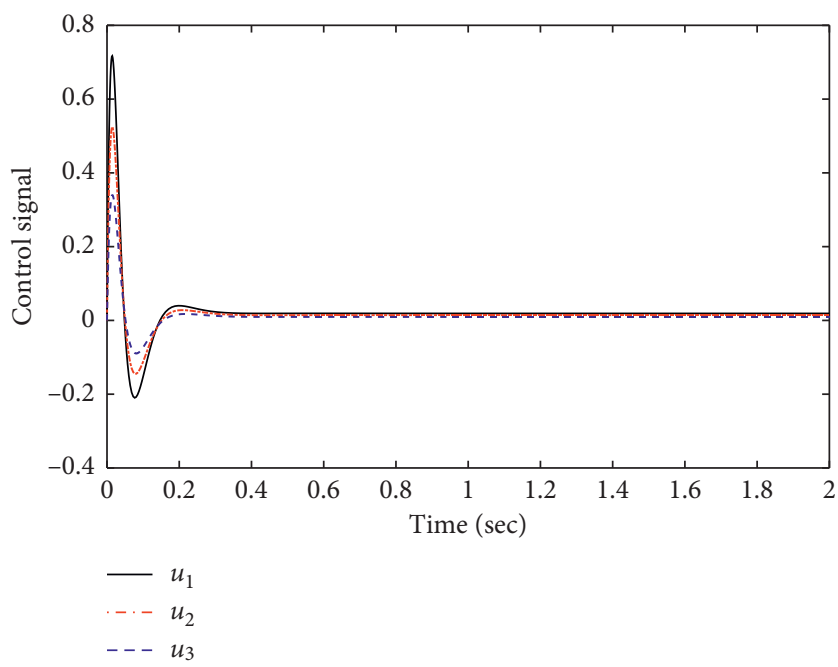

Figure 4: Control signal of the system.

TABLE 2: Comparison between the proposed AISOSMC method with the previous method in [22].

\begin{tabular}{lcccc}
\hline Kinds of controller & \multicolumn{2}{c}{ The AISOSMC approach } & \multicolumn{2}{c}{ Previous load frequency controller in } \\
Parameters & $T_{s}(\mathrm{~s})$ & Max. O. $S(\mathrm{pu})$ & $T_{s}(\mathrm{~s})$ & Max. O. $S(\mathrm{pu})$ \\
\hline$\Delta f_{1}$ & 1 & $-3.8 \times 10^{-3}$ & 2 & $-3.8 \times 10^{-3}$ \\
$\Delta f_{2}$ & 1 & $-2.1 \times 10^{-3}$ & 2 & $-2.1 \times 10^{-3}$ \\
$\Delta f_{3}$ & 1 & $-1.9 \times 10^{-3}$ & 2 & $-2.0 \times 10^{-3}$ \\
\hline
\end{tabular}

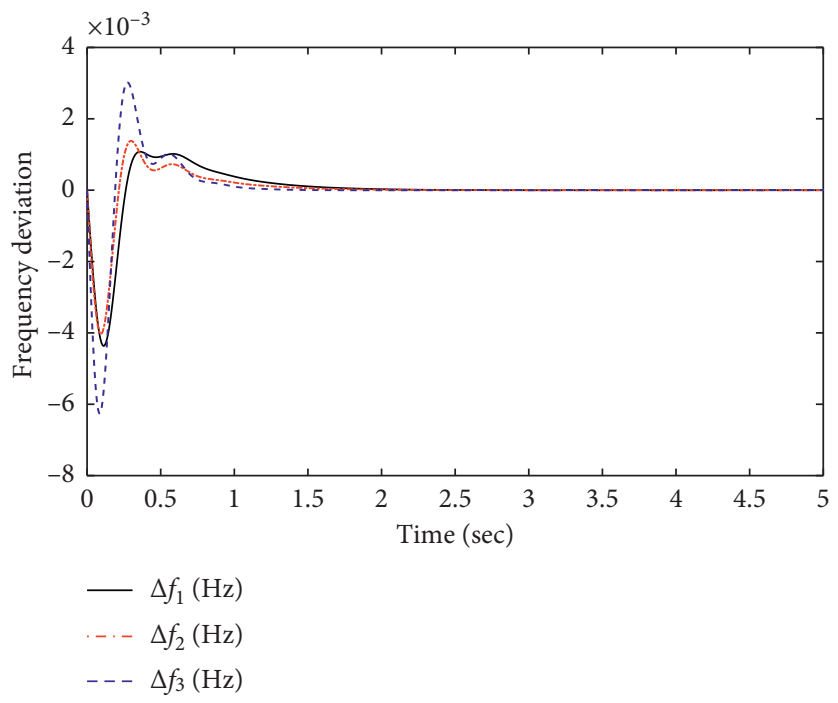

FiguRE 5: Frequency deviation of the system under matched uncertainty.

AISOSMC always are kept with maximum value as $4.7 \times 10^{-3}$ p.u.MW in Figure 7 .

Remark 5. In this configuration, the influents of time-delay signals are considered to compare with the simulation result in [22], the DAISOSMCL based on the offered switching surface can not only make better in the response speed but also upgrade the transient performance to decrease the overshoot percentage. So, the designed control method is powerful and strong enough to regulate and control the matched parameter uncertainties of multiarea interconnected time-delay grids.

Case 3. In this case, the load disturbances are $\Delta P_{d 1}=0.01$ p.u.MW at $t_{1}=0 \mathrm{~s}, \Delta P_{d 2}=0.02$ p.u.MW at $t_{2}=0$, and $\Delta P_{d 3}=0.03$ p.u.MW at $t_{3}=0$ in area 1 , area 2 , and area 3 , 


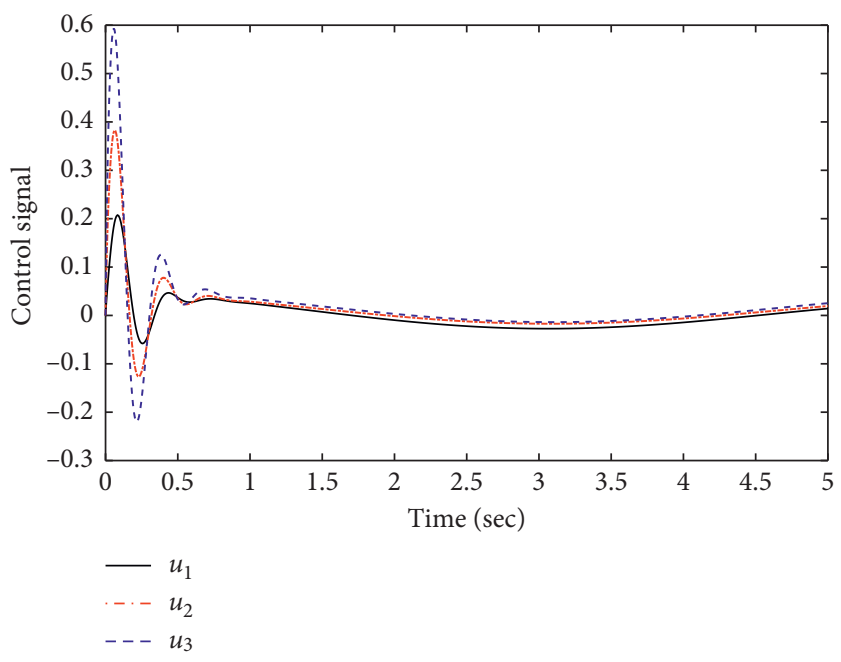

FIGURE 6: Control signal of the system under matched uncertainty.

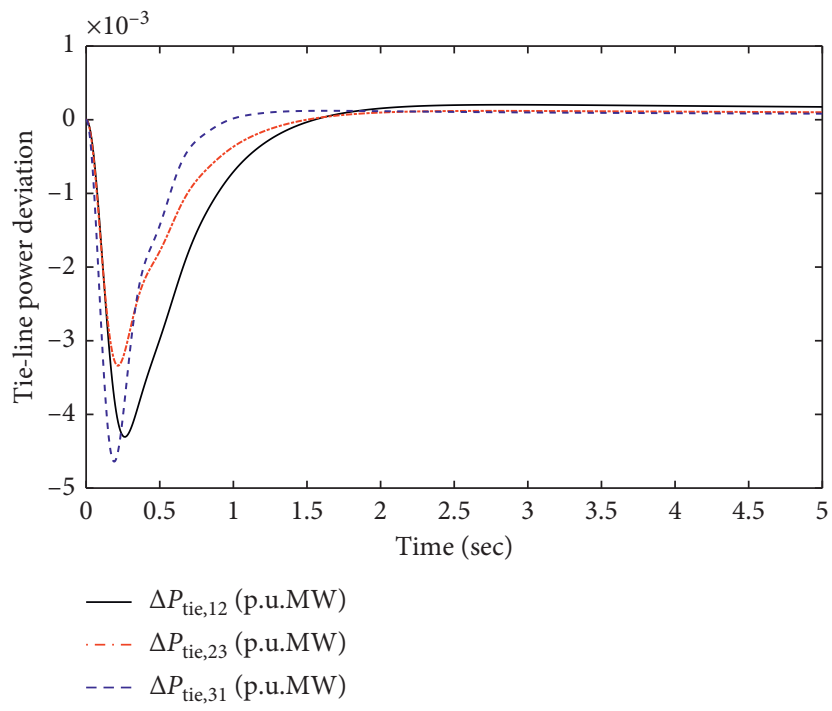

Figure 7: Tie-line deviation of the system under matched uncertainty.

respectively. We discuss about the impact of mismatch parameter uncertainty in the state matrix and values of the time-delay as $\tau_{i}=0.2 \mathrm{~s}(i=1,2,3)$ for all the subsystems of LSPSwCD which are designed as follows:

$$
\begin{aligned}
\Delta A_{1} & =\left[\begin{array}{ccccc}
0 & \Delta f_{1} & 0 & 0 & 0 \\
\sin (t) & 0 & 0 & 0 & 0 \\
0 & 0 & \cos (t) & \cos (t) & 0 \\
0 & 0 & 0 & 0 & \cos (t) \\
\cos (t) & 0 & 0 & 0 & 0
\end{array}\right], \\
\Delta A_{2} & =\Delta A_{3}=\Delta A_{1} .
\end{aligned}
$$

The mismatch interconnected between subsystems is designed as follows:

$$
\begin{aligned}
\Delta H_{12} & =\left[\begin{array}{ccccc}
0 & 0 & 0 & 0 & 0.178 \cos (t) \\
0 & 0 & 0 & 0 & 0 \\
0 & 0 & 0 & 0 & 0 \\
0 & 0 & 0 & 0 & -0.296 \sin (t) \\
0 & 0 & 0 & 0 & 0
\end{array}\right], \\
\Delta H_{12} & =\Delta H_{23}=\Delta H_{31} .
\end{aligned}
$$

The frequency variation in LSPSwCD is displayed in Figure 8, the control input signal is presented in Figure 9, and tie-line power variation is displayed in Figure 10. We observe the system performance, the transient response makes achievement by the proposed control scheme which reduces the amplitude of over/undershoot percentage. It is 


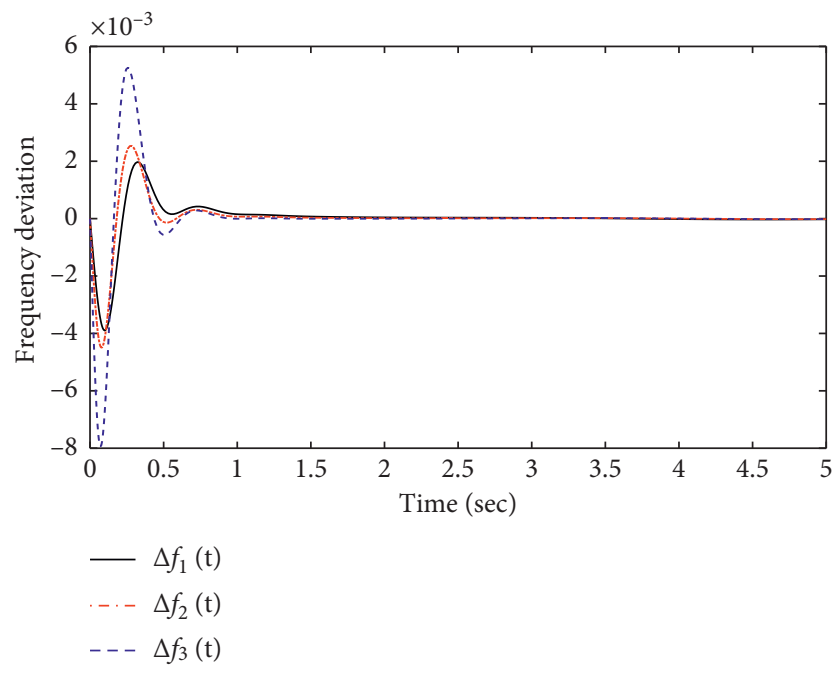

Figure 8: Frequency deviation of the system under mismatched uncertainty.

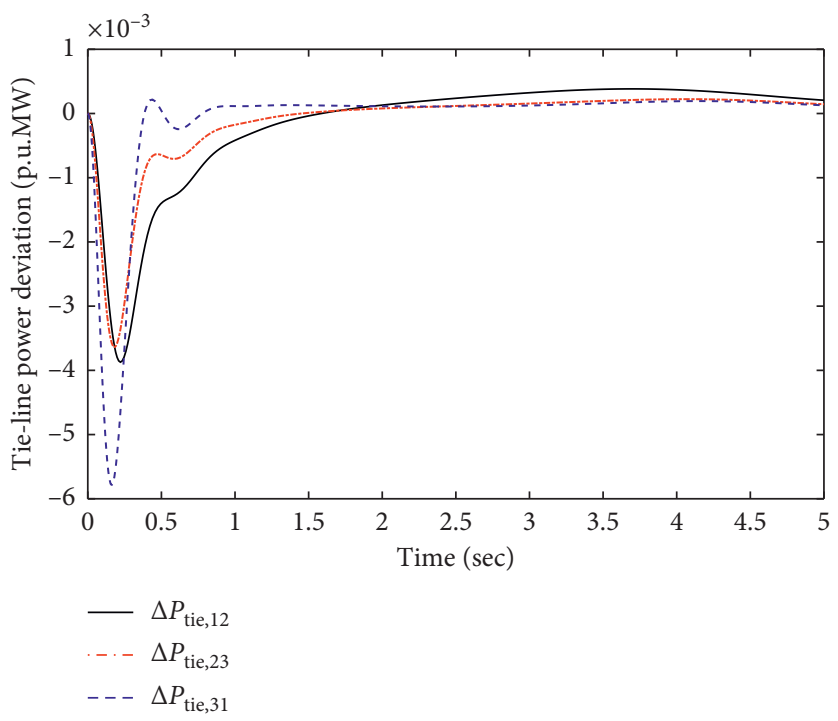

FIgURE 9: Tie-line deviation of the system under mismatched uncertainty.

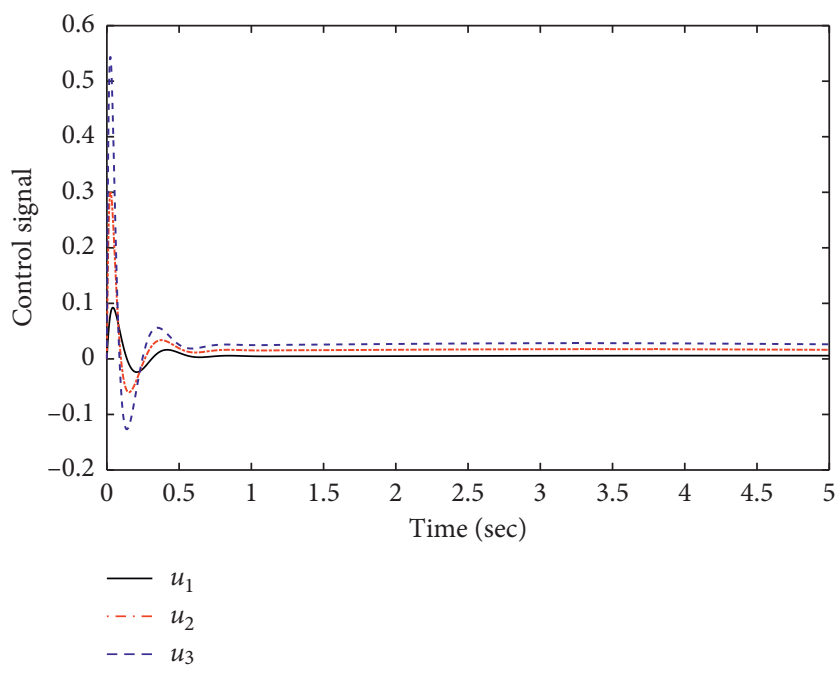

FIgURE 10: Control signal of the system under mismatched uncertainty. 


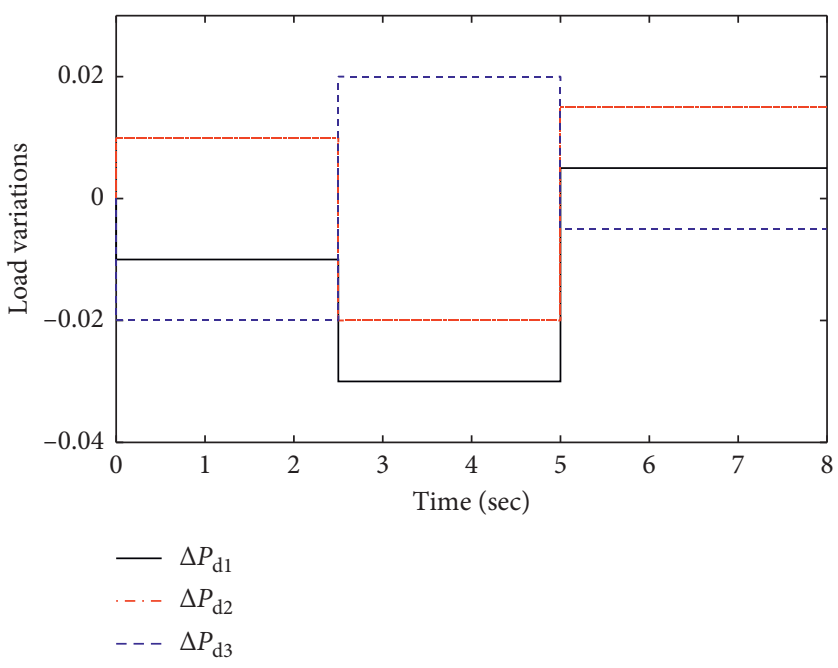

FIGURE 11: Load variations of three-area power network.

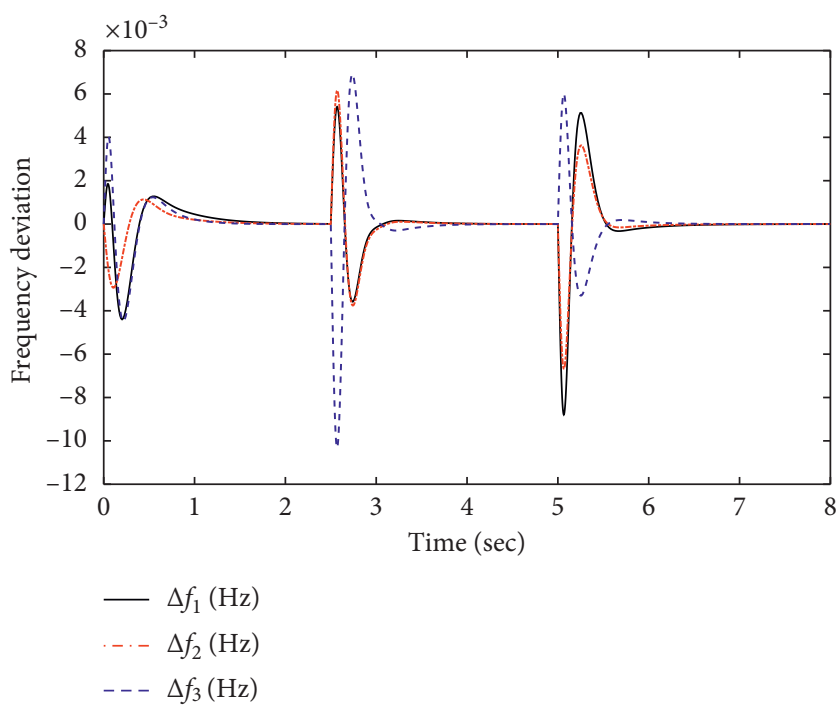

FIGURE 12: Frequency variation of the system under load variations and mismatched uncertainty.

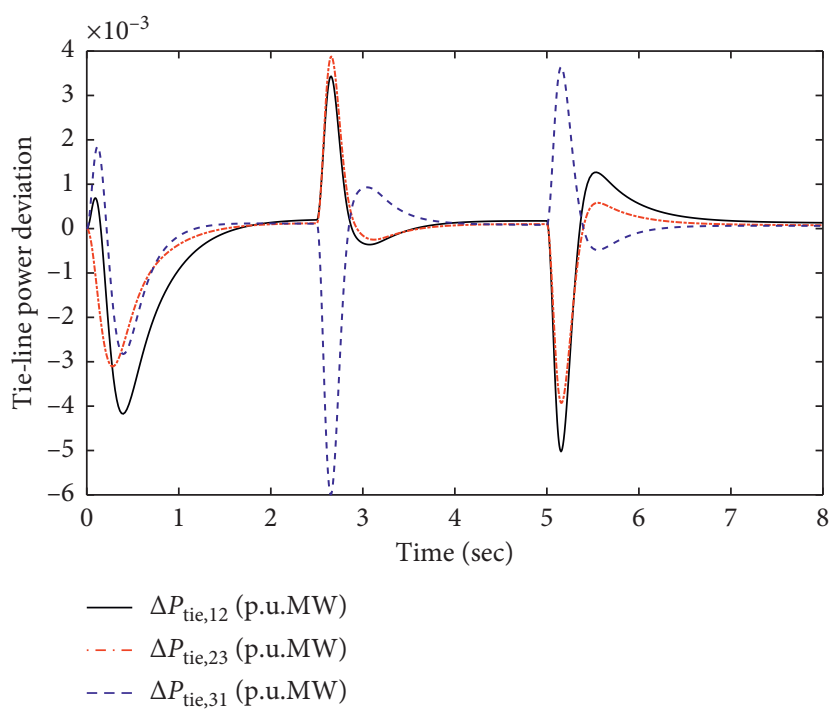

FIGURE 13: Tie-line power variation of the system under load variations and mismatched uncertainty. 


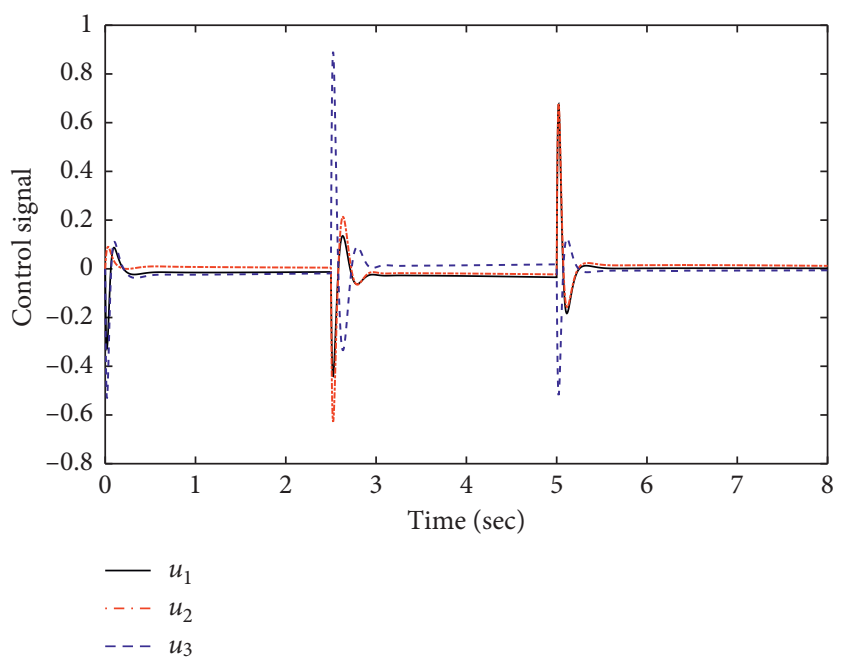

FIGURE 14: Control signal of the system under load variations and mismatched uncertainty.

to be clear that the input control signal is to converge quickly and drive the tie-line power variation and frequency variation to zero. Therefore, the suggested controller carried out with better design, both in terms of reducing the over/undershoots and minimizing the settling time in comparison to $[21,22]$.

Remark 6. In this case, though considering to the influence of the mismatched uncertainty of LSPSwCD, the performance of proposed controller still is kept powerful and stable. Therefore, the proposed ISOSMC is proved to be suitable for LSPSwCD. The approach given in $[21,22]$ cannot be applied for the LSPSwCD of this case.

Case 4. In this case, the nominal parameters of LSPSwCD are in Table 1 and the same parameters with previous cases. However, in the practical power system, the parameters of LSPSwCD are always varied due to different operation conditions. Therefore, the parameters of LSPSwCD are selected to vary by $\pm 20 \%$ synchronously from their normal values. The delay time is $0.2 \mathrm{~s}$ and load variation is as shown in Figure 11. The tie-line power and frequency deviation decay quickly as observed in Figures 12 and 13. The control signal has been presented in Figure 14. It is to be clear that the proposed control scheme is able to handle with the timedelay and random load disturbances. It is proved that the proposed DAISOSMCL has the good quality and achievement to reject disturbance with small control signal.

Remark 7. In this approach, the structure of LSPSwCD is more general than the approach given in [28-33]. Also, the system responses in terms of convergence of frequency variation and power exchange error are improved by using the proposed DAISOSMCL. Therefore, the proposed design controller is suitable for LFC of LSPSwCD.

\section{Conclusions}

In this paper, the LFC based on decentralized adaptive integral second-order sliding mode control (DAISOSMC) has been developed for the large-scale power system with communication delays (LSPSwCD), load variations, and parameter uncertainties. It is shown that the proposed DAISOSMCL ensures the finite time reachability of the system states and moreover the dynamics of LSPSwCD in the sliding mode is asymptotically stable under certain conditions. To the best of our knowledge, this is the first time the DAISOSMC approach is designed for LFC of the LSPSwCD. The report of simulation results indicates that the proposed DAISOSMC approach can adequately make less the deviation of the tie-line power and frequency variation of LSPSwCD. The suggested control scheme is therefore proved to be more effective for the LSPSwCD implementation.

\section{Data Availability}

Data used to support the findings of this study are included within the article.

\section{Conflicts of Interest}

The authors declare no conflicts of interest.

\section{Acknowledgments}

This research was funded by the Foundation for Science and Technology Development of Ton Duc Thang University (FOSTECT), website: http://fostect.tdtu.edu.vn, under Grant FOSTECT.2017.BR.05.

\section{References}

[1] D. Guha, P. K. Roy, and S. Banerjee, "Load frequency control of interconnected power system using grey wolf 
optimization," Swarm and Evolutionary Computation, vol. 27, pp. 97-115, 2016.

[2] M. Ma, C. Zhang, X. Liu, and H. Chen, "Distributed model predictive load frequency control of the multi-area power system after deregulation," IEEE Transactions on Industrial Electronics, vol. 27, pp. 5129-5139, 2016.

[3] K. Liao and Y. Xu, "A robust load frequency control scheme for power systems based on second-order sliding mode and extended disturbance observer," IEEE Transactions on Industrial Informatics, vol. 14, no. 7, pp. 3076-3086, 2017.

[4] K. P. S. Parmar, S. Majhi, and D. P. Kothari, "LFC of an interconnected power system with multi-source power generation in deregulated power environment," International Journal of Electrical Power \& Energy Systems, vol. 57, pp. 277-286, 2014.

[5] V. Çelik, M. T. Özdemir, and K. Y. Lee, "Effects of fractionalorder PI controller on delay margin in single-area delayed load frequency control systems," Journal of Modern Power Systems and Clean Energy, vol. 7, no. 2, pp. 380-389, 2019.

[6] R. Dey, S. Ghosh, G. Ray, and A. Rakshit, "Ho load frequency control of interconnected power systems with communication delays," International Journal of Electrical Power \& Energy Systems, vol. 42, no. 1, pp. 672-684, 2012.

[7] Y. Cui, G. Shi, L. Xu, X. Zhang, and X. Li, "Decentralized Ho load frequency control for multi-area power systems with communication uncertainties," In Advanced Computational Methods in Energy, Power, Electric Vehicles, and Their Integration, vol. 4, pp. 429-438, 2017.

[8] H. Zhang, J. Liu, and S. Xu, "H-infinity load frequency control of networked power systems via an event-triggered scheme," IEEE Transactions on Industrial Electronics, vol. 67, no. 8, pp. 7104-7113, 2019.

[9] S. Prasad, S. Purwar, and N. Kishor, "H -infinity based nonlinear sliding mode controller for frequency regulation in interconnected power systems with constant and timevarying delays," IET Generation, Transmission \& Distribution, vol. 10, no. 11, pp. 2771-2784, 2016.

[10] M. N. Anwar and S. Pan, "A new PID load frequency controller design method in frequency domain through direct synthesis approach," International Journal of Electrical Power \& Energy Systems, vol. 67, pp. 560-569, 2015.

[11] S. Sondhi and Y. V. Hote, "Fractional order PID controller for load frequency control," Energy Conversion and Management, vol. 85, pp. 343-353, 2014.

[12] S. Saxena and Y. V. Hote, "Decentralized PID load frequency control for perturbed multi-area power systems," International Journal of Electrical Power \& Energy Systems, vol. 81, pp. 405-415, 2016.

[13] N. Kouba, M. Menaa, K. Tehrani, and M. Boudour, "Optimal tuning for load frequency control using ant lion algorithm in multi-area interconnected power system," Intelligent Automation \& Soft Computing, vol. 25, no. 2, pp. 279-294, 2019.

[14] H. A. Yousef, K. AL-Kharusi, M. H. Albadi, and N. Hosseinzadeh, "Load frequency control of a multi-area power system: an adaptive fuzzy logic approach," IEEE Transactions on Power Systems, vol. 29, no. 4, pp. 1822-1830, 2014.

[15] M. Gheisarnejad and M. H. Khooban, "Design an optimal fuzzy fractional proportional integral derivative controller with derivative filter for load frequency control in power systems," Transactions of the Institute of Measurement and Control, vol. 41, no. 9, pp. 2563-2581, 2019.

[16] D. Xu, J. Liu, X. Yan, and W. Yan, "A novel adaptive neural network constrained control for multi-area interconnected power system with hybrid energy storage," IEEE Transactions on Industrial Electronics, vol. 65, no. 8, pp. 6625-6634, 2017.

[17] Z. Sun, F. Xing, S. Che, B. Hu, and D. Sun, "Designing and optimization of fuzzy sliding mode controller for nonlinear systems," Computers, Materials \& Continua, vol. 61, no. 1, pp. 119-128, 2019.

[18] Q. Zhu and Z. Yang, "Intelligent power compensation system based on adaptive sliding mode control using soft computing and automation," Computer Systems Science and Engineering, vol. 34, no. 4, pp. 179-189, 2019.

[19] K. Khayati, "Multivariable adaptive sliding-mode observerbased control for mechanical systems," Canadian Journal of Electrical and Computer Engineering, vol. 38, no. 3, pp. 253265, 2015.

[20] D. Qian and G. Fan, "Neural-network-based terminal sliding mode control for frequency stabilization of renewable power systems," IEEE/CAA Journal of Automatica Sinica, vol. 5, no. 3, pp. 706-717, 2018.

[21] B. Le Ngoc Minh, V. V. Huynh, T. M. Nguyen, and Y. W. Tsai, "Decentralized adaptive double integral sliding mode controller for multi-area power systems," Mathematical Problems in Engineering, vol. 2018, Article ID 2672436, 11 pages, 2018.

[22] M. K. Sarkar, A. Dev, P. Asthana, and D. Narzary, "Chattering free robust adaptive integral higher order sliding mode control for load frequency problems in multi-area power systems," IET Control Theory \& Applications, vol. 12, no. 9, pp. 1216-1227, 2018.

[23] S. Prasad, S. Purwar, and N. Kishor, "Non-linear sliding mode load frequency control in multi-area power system," Control Engineering Practice, vol. 61, pp. 81-92, 2017.

[24] D. Qian, S. Tong, and X. Liu, "Load frequency control for micro hydro power plants by sliding mode and model order reduction," Automatika, vol. 56, no. 3, pp. 318-330, 2015.

[25] J. Guo, "Application of full order sliding mode control based on different areas power system with load frequency control," ISA Transactions, vol. 92, pp. 23-34, 2019.

[26] J. Guo, "Application of a novel adaptive sliding mode control method to the load frequency control," European Journal of Control, vol. 12, pp. 3050-3071, 2020.

[27] Y. Mi, Y. Fu, C. Wang, and P. Wang, "Decentralized sliding mode load frequency control for multi-area power systems," IEEE Transactions on Power Systems, vol. 28, no. 4, pp. 4301-4309, 2013.

[28] S. K. Pradhan and D. K. Das, "Ho Load frequency control design based on delay discretization approach for interconnected power systems with time delay," Journal of Modern Power Systems and Clean Energy, vol. 2, pp. 1-10, 2020.

[29] C. Fu and W. Tan, "Decentralized load frequency control for power systems with communication delays via active disturbance rejection," IET Generation, Transmission \& Distribution, vol. 12, no. 6, pp. 1397-1403, 2017.

[30] C. Fu, C. Wang, L. Y. Wang, and D. Shi, “An alternative method for mitigating impacts of communication delay on load frequency control," International Journal of Electrical Power \& Energy Systems, vol. 119, Article ID 105924, 2020.

[31] A. E. Onyeka, Y. Xing-Gang, Z. Mao, B. Jiang, and Q. Zhang, "Robust decentralized load frequency control for interconnected time delay power systems using sliding mode techniques," IET Control Theory and Applications, vol. 14, no. 3, pp. 470-480, 2019.

[32] Y. Sun, Y. Wang, Z. Wei, G. Sun, and X. Wu, "Robust Ho load frequency control of multi-area power system with time delay: a sliding mode control approach," IEEE/CAA Journal of Automatica Sinica, vol. 5, no. 2, pp. 610-617, 2017. 
[33] Y. Mi, X. Hao, Y. Liu et al., "Sliding mode load frequency control for multi-area time-delay power system with wind power integration," IET Generation, Transmission \& Distribution, Transmission \& Distribution, vol. 11, no. 18, pp. 4644-4653, 2017.

[34] S. Boyd, E. L. Ghaoui, E. Feron, and V. Balakrishna, "Linear matrix inequalities in system and control theory," Society for Industrial and Applied Mathematics, vol. 15, 1994.

[35] V. V. Huynh, Y.-W. Tsai, and P. V. Duc, "Adaptive output feedback sliding mode control for complex interconnected time-delay systems," Mathematical Problems in Engineering, vol. 2015, Article ID 239584, 15 pages, 2015.

[36] X.-G. Yan, S. K. Spurgeon, and C. Edwards, "Global decentralised static output feedback sliding-mode control for interconnected time-delay systems," IET Control Theory \& Applications, vol. 6, no. 2, pp. 192-202, 2012. 